\title{
Learning through collaboration between vocational teacher training institutions and workplaces: Barriers and contradictions
}

\author{
Dinavence Arinaitwe ${ }^{1}$, Louise Mifsud ${ }^{1}$, \\ Habib Kato ${ }^{2} \&$ Arne Ronny Sannerud ${ }^{3}$ \\ ${ }^{1}$ Oslo Metropolitan University, Norway, ${ }^{2}$ Kyambogo University, Uganda, \\ ${ }^{3}$ University College of Vocational Education, Norway \\ (arinaitwedinavence@gmail.com)
}

\begin{abstract}
In vocational education and training, the acquisition of relevant skills by learners is vital for their employability. It has been argued that institution-workplace collaboration facilitates this acquisition of relevant skills through availing authentic real-life learning situations. This study used the cultural-historical activity theory to identify and characterise challenges to learning through collaboration between a masters of vocational pedagogy (MVP) programme, vocational teacher training institutions and workplaces in Uganda. Data were obtained using in-depth individual interviews with purposively sampled actors in collaborative activities. The findings revealed that challenges manifesting as discursive contradictions occurred in different phases of implementing collaborative activities. In the planning and implementation phase, contradictions were linked to short time frames for collaborative activities, unsynchronised activity plans and contradictory working cultures. In the supervision of learning, contradictions arose from a lack of a common understanding of the objectives and work methods of the collaborative activities. A lack of feedback to actors, an absence of a collaboration focal person, and a lack of government policy limited participation in collaborative activities. These challenges were observed to lessen the focus on the MVP students' learning, which ultimately affected the quality of work produced and interfered with the implementation of collaborative activities.
\end{abstract}

Keywords: institution-workplace collaboration, contradictions, collaborative activities, action research, vocational pedagogy

NJVET, Vol. 12, No. 1, 25-50

https:// doi.org/10.3384/njvet.2242-458X.2212125

Peer-reviewed article

Hosted by Linköping University Electronic Press @ The authors 


\section{Introduction}

Vocational education and training (VET) aims to ensure that the learning outcomes meet the competences required for employment and entrepreneurship in the labour market (Köpsén \& Andersson, 2018; United Nations, 2015). However, the achievement of VET learning outcomes reflects a need for collaboration between educational institutions and workplaces in ensuring the relevance of the programmes (Arinaitwe, 2021; Mårtensson, et al., 2019). While the emerging vocational practices and technological changes pose significant challenges, VET professionals are challenged to develop, adapt or redesign strategies to address the needs of workers and society (Rojewski, 2009).

First, for VET teachers and educators, Andersson and Köpsén (2019) advocated for boundary processes between schools and workplaces to keep abreast of the industrial currency of their own occupational knowledge and skills if they are to produce competent graduates. A country like South Africa has proposed a policy on the professional development of technical and vocational teacher education programmes to include, in addition to teaching practice, industry-based work-integrated learning; to ensure that the lecturers understand the labour market demands and be able to produce graduates who meet these demands (Batholmeus \& Pop, 2019). Secondly, it has been argued that for VET students to develop the competences required in the world of work, learning programmes need to include a community of practice and pathways of participation in social practice (Said, 2018). According to Billett (2001), vocational expertise can be developed if students have the opportunity to access and participate in practice.

Several research studies conducted both in VET (Flynn et al., 2016) and vocation teacher education (Arinaitwe \& Sannerud, 2019) have emphasised the importance of institutional-workplaces collaboration (IWC) in producing competent trainers and/or workers. Flynn et al. (2016) revealed that IWCs allow for the convergence of partner perspectives that stimulate innovative solutions. The Organisation for Economic Co-operation and Development (OECD, 2010) observed that efficient IWCs help individuals attain job ready skills and to gain an understanding of the work. Thus, Bound (2011) advocated for vocational teacher training to take place through both formal sessions and workplace learning avenues, provided for by IWCs.

However, despite the arguments for strengthening IWCs, several research studies have revealed challenges in putting these collaborations into practice (Ankrah \& Al-Tabbaa, 2015). While these challenges have been extensively researched in the global north and relatively well studied in global south and transitional economies, focus has mostly been on general VET and higher education. Little published data exists on IWC in vocational teacher education generally and particularly for the Ugandan context (Kitagaana, 2018). As such, this study aims to identify and characterise the challenges of learning through collaboration 
between a masters in vocational pedagogy (MVP) programme, vocational teacher training institutions (VTIs) and workplaces in Uganda. We raise the following questions:

1. What challenges can be identified in learning through collaboration among the MVP, vocational teacher training institutions and workplaces?

2. How are learning activities in the MVP programme influenced by these challenges?

In this paper we employ the phrase institution-workplace collaboration (IWC) similarly to Ankrah and Al-Tabbaa (2015) who described it as an interaction between any parts of the educational institutions and workplaces with the aim of encouraging exchange of knowledge, technology and expertise.

The rest of the paper is organised as follows: a brief contextual background of the MVP programme, a short literature review, the theoretical framework used in this study, methodology and finally the presentation, analysis and discussion of our findings.

\section{Vocational teacher education in Uganda}

The training of instructors and technical teachers in Uganda is an integral part of VET that is administered by the Ministry of Education and Sports (MoES) under the department of teacher/tutor/instructor education and training (MoES, 2012). To teach VET disciplines at national craft level requires that one has completed a diploma course at vocational teacher training institutions/instructor colleges (referred to as VTIs in this study). For teaching at higher levels, that is, diploma and beyond, degrees and other postgraduate studies in the technical and pedagogy fields attainable at universities and other tertiary institutions are required.

According to the Technical, Vocational Education and Training Policy of 2019 (MoES, 2019a) the VET system in Uganda is generally characterised as theorybased education, where the delivery methods are largely theoretical and academic. Under such conditions, learning tends to be mainly teacher-centred (Okello, 2011); which limits the acquisition of practical competencies of VET graduates and their income generation (MoES, 2012, 2019b). While the National Teacher Policy of 2019 (MoES, 2019b) attributed the inadequate practical competences of VET graduates to the shortage of technically and pedagogically qualified teachers and teacher educators, ineffective teaching, low qualifications and standards, other issues are at play (see also Arinaitwe, 2021).

Despite the existing education system being largely theory-based and teachercentred (MoES, 2019a), the MVP programme at Mukinga University (pseudonym) in Uganda offers an alternative approach to learning that is learner-centred. However, in Uganda, vocational pedagogy seems to be a new phenomenon that can be traced back to the inception of the MVP programme in 2008. VET in 
Uganda has been significantly influenced by the culture adopted from the British education system previously in place in the country (Okello, 2014). These systems were predominantly teacher-centred and, thus, can be a source of tension in the introduction of vocational pedagogy, which employs learner-centred teaching strategies.

\section{MVP programme at Mukinga University in Uganda}

The MVP programme included in this study is an initiative aimed at strengthening collaboration between Mukinga University in Uganda, educational institutions and workplaces (industries and organisation), to integrate academic and workplace learning. The programme was funded by the Norwegian Programme for Capacity Development in Higher Education and Research Development MVP project from 2013-2018. The MVP programme is structured around a vocational pedagogy; a field of knowledge-oriented towards occupations in developing appropriate teaching, research methods, and curricula (Sannerud, 2019). Vocational pedagogy is also a learner-centred approach to teaching and learning where the relationship between the student and the task is central, performing work activity socially and/or independently is a pillar for learning and the students have authority over their work (Mjelde \& Daly, 2012).

The programme encompasses collaborative activities herein referring to workplace activities, such as, field expeditions and action research projects initiated by the MVP to support 'back-and-forth' learning in workplaces. The 'back-andforth' learning entails the collaborative process in which the students move between learning in educational institutions and the workplace.

The MVP programme recruits students from all vocational backgrounds including; vocational teacher education, health, business, languages and her graduates qualify to teach in any of those fields. Three cohorts of 59 MVP students undertook action research projects in their workplaces and/or VTIs, aimed at solving challenges encountered in their work or teaching practices. The second cohort MVP students, who are vocational teacher educators at the VTIs, were considered in this study. The action research projects entailed collaboratively engaging the VTI actors (administrators, staff and students) in identifying the problems in their teaching processes, planning actions, taking action, evaluating the consequences of the actions and identifying the learning outcomes. The MVP mentors planned and organised daily learning at the programme and, together with the action research supervisors, support the implementation of the projects. The project administrators monitor and support the implementation of the programme activities.

Arinaitwe and Sannerud (2019) in their previous study found that implementing collaborative activities in the MVP benefited the actors in the following ways: (1) The collaborative activities promoted learning through interactions by 
allowing actors to share experiences. (2) Participation in field expeditions facilitated the learning of various components of the MVP programme through engaging in real-life tasks and learning from one another. (3) By engaging in action research projects, the actors acquired competencies in designing and creating different items and also developed critical thinking skills. (4) Collaborative activities became an avenue for education institutions to identify future trainers. Although several learning opportunities stemming from collaborative activities have been identified, the current paper mainly focuses on the barriers and contradictions that emerge during the implementation process. This background formed the basis for investigating the contradictions arising from learning through collaboration between the MVP, VTIs and workplaces.

\section{Literature review}

Several research studies have presented and categorised the challenges hindering effective IWCs (Ankrah \& Al-Tabbaa, 2015; Rybnicek \& Konigsgruber, 2019; Sjöö \& Hellström, 2019) and thus limiting learning from these partnerships (Maxwell, 2014; Mikkonen et al., 2017) both in global north and south. Whereas these categories are cross-cutting, in the following section, we build on the existing categories to discuss the challenges to learning through IWC.

\section{Planning and structuring of work and/or learning activities}

Billett (2001) observed that the structuring of workplace practices sometimes inhibits access which limits employees' understanding of workplace goals, especially when seniority is used to determine opportunities to access new kinds of experiences. Maxwell (2014) concurred, noting that the structuring of work affects the trainees' abilities to gain sufficient practice by completing key tasks and functions for achieving competencies. Similarly, Taylor (2006) observed that changes in work practices in institutions may also create tensions that affect the development of partnerships. For instance, Jackson et al.'s (2019) study conducted in Australia revealed that the students found challenges in applying the knowledge and skills acquired from the university to work-related contexts. The students attributed their inability to transfer learning experiences to shorter time frames for industrial placements.

\section{Mentors/supervisor support}

Batholmeus and Pop (2019) identified mentor support as a crucial aspect of workplace learning, whose role should be carefully considered, understood and contributed by all stakeholders. Mentors help ensure that trainees acquire knowledge of workplace culture, norms and practices, situational understanding as well as facilitate the application and transfer of different skills and personal 
attributes to production (Jackson et al., 2019). As such, the absence of mentor support would deny trainees both emotional support and opportunities to gain feedback on their practices (Maxwell, 2014). Furthermore, failure by the workplace mentors to commit to guidance could result in insufficient support for learning (Mikkonen et al., 2017) as well as limit access to knowledge that would not be learned through discovery (Billett, 2001). Students in Jackson et al.'s (2019) study attributed their inability to transfer learning experiences to work-context to limited guidance from the workplace co-workers and supervisors, who were too busy with work and hardly could reserve any time to guide them. Besides, even to some workplaces, production schedules are rather more important than guiding and instructing trainees' learning; an environment that is un-conducive for workplace learning (Mikkonen et al., 2017).

\section{Organisational culture}

Previous research studies (Ankrah \& Al-Tabbaa, 2015; Sá, 2013) have indicated that cultural differences between academia and industry continue to limit learning from IWCs. For example, financial gain is the main motivation for those in industry, while for university scientists, the focus is community recognition through publication (Guimon, 2013). As such, if an industry is driven by an intense desire for profit, there is a likelihood that the manager may not allow the employees some time to supervise and teach the student the job practices which restrained learning (Mårtensson et al., 2019). Kitagaana (2018) emphasised that the disparities in goals and priorities also generate a lack of confidence on the part of universities as potential partners.

\section{Institutional capacity issues}

Recent research (Sjöö \& Hellström, 2019) has shown that IWC is further hampered by management and organisation capacity issues. Several research studies (Choy et al., 2016; Pertuze et al., 2010) emphasised the need to develop institutional capacity to create an environment, start, maintain, support and sustain partnerships. For instance, the role of boundary spanners (herein referred to as collaboration focal persons), as persons who network within and between partner institutions, is highly emphasised (Pertuze et al., 2010). Whereas different authors reveal a variation in the usage of the term boundary spanners, the common connotations include collaboration champion person, technology transfer officers, contact person and industrial liaison officers (Ankrah \& Al-Tabbaa, 2015; Guimon, 2013). Sá (2013) noted that training institutions - especially in Africa lack such structures and qualified staff to coordinate and engage productively with industry. Kitagaana's (2018) study conducted in Uganda affirmed the absence of industrial liaison officers and technology transfer officers.

According to Sjöö and Hellström (2019), boundary spanners help to establish and maintain efficient communication channels between university researchers 
and the industry. Consequently, the absence of boundary spanners leaves the responsibility for learning from and fostering collaborations with a few individuals (Sá, 2013). Mårtensson et al. (2019) found that organising collaborative activities is in most cases left to institute teachers and workplace employees who are also overloaded with teaching and production schedules, thus constraining learning from these collaborations. While crossing organisational boundaries may give rise to changes in formal structures, particularly those of training institutions, Sjöö and Hellström (2019) observed that its effects have not yet been ascertained.

\section{Institutional resource issues}

Sjöö and Hellström (2019) reported that IWCs are further hampered by inadequate resources, such as funding, structures and facilities (equipment and time). And yet, Rybnicek and Konigsgruber's (2018) study revealed that the quality of collaboration depends on the resources that actors are willing to offer. However, a study conducted in Africa (Sá, 2013) revealed that training institutions are not equipped with the necessary infrastructure to train students to meet the demands of industry. In this regards, Guimon (2013) cited insufficient funds as limiting training institutions' ability to build relevant research programmes in the fields of interest to industry.

Concerning the aspect of time, a study by Ellinger and Cseh (2007) found that staffs from training institutions lack the time to engage in collaborative activities due to heavy workloads. In a study conducted in Uganda, Mushemeza (2016) echoed increased teaching load of lecturers as lowering their level of participation in research. Moreover, the more time the VET teachers engage in authentic work, interact with workplace professionals, the greater their potential of acquiring current occupational competencies and identity (Köpsén \& Andersson, 2018). However, as previously indicated, workplaces employees like teachers lack the time to engage and guide trainees in acquiring job practices (Jackson et al., 2019; Mårtensson et al., 2019; Mikkonen et al., 2017). And yet, timely and guided interventions by the trainers are vital for students in understanding the nature of the difficulties they are facing in particular tasks (Fjellström, 2014). As such, Mikkonen et al. (2017) identified a need for trainers to be allotted sufficient time in the production schedule for training and for supervising collaborative activities.

\section{Legal and/or political issues}

Another challenge facing IWCs is legal issues, including government and institutional policies, intellectual property rights, and contractual mechanisms (Ankrah \& Al-Tabbaa, 2015). For most developing countries in Africa, Mgonja (2017) revealed the absence of clear policies to encourage IWCs. In Uganda in particular, the absence of comprehensive systematic legislation to regulate and support IWC and the lack of consistent programmes to encourage such partnerships are persistent issues in VET (Kalanda et al., 2021). In contrast, for developed 
nations, such as Sweden, too many or unclear rules and excessive legal frameworks limit IWC (Sjöö \& Hellström, 2019).

From the literature review, we observe that several issues of varying dimensions constrain IWCs and thus hinder learning from these collaborations. Despite the existing extensive research, these mainly focus on broad analysis of challenges to IWC generally in VET and higher education. Therefore, more research is needed to analyse how challenges to IWC influence learning activities in vocational teacher education (herein MVP programme in consideration).

\section{Theoretical framework:}

\section{Contradictions within a human activity system}

This study seeks to identify and characterise the challenges of learning through collaboration between MVP, VTIs and workplaces. We take a cultural-historical activity theory (CHAT) approach focusing on contradictions within human activity systems as the point of departure. CHAT addresses the complex interrelations among the subject, the object and a community of two or more interacting activity systems (Engeström, 2001). A human activity system refers to $a$ network of actors, collectively and socially acting together in all its elements (Engeström, 2015). Figure 1a (below) shows the elements of the MVP programme as a central activity system. These elements comprise the subjects (i.e., the individuals or groups performing an activity) and the object (i.e., the problem space at which the activity is directed). The object is turned into an outcome with the help of instruments - tools and signs. The elements act within a community comprising individuals or groups who share the same object. There is also a division of labour (i.e., a horisontal division of tasks and vertical division of power). The activity system elements conform to rules - regulations, norms, conventions and standards that may constrain actions within the system (Engeström \& Sannino, 2010).

In this article, we focus on the interrelationship between three activity systems: an MVP programme, workplaces (organisations and industries) and VTIs. When two or more activity systems interact, they generate a shared object, which in this case is participation in collaborative activities; they also develop new patterns of activity as well as tensions and contradictions (Engeström, 2001, 2015), as shown in Figure 1. Contradictions are accumulated structural tensions within and between activity systems (Engeström, 2001; Daniels et al., 2007). Contradictions are systemic, though not directly observed; they manifest and arise in actions, interactions and discourse (Engeström \& Sannino, 2011). In this article, we take as our focus the discursive form of the manifestation of contradictions. Discursive contradictions are manifested and constructed in the patterns of speech and actions that actors try to make sense of, deal with, transform or resolve (Engeström \& 
Sannino, 2011). Engeström and Sannino (2011) further categorised the discursive manifestation of contradictions as dilemmas, conflicts, critical conflicts, and double binds. Disturbances and local innovations are also manifestations of contradictions (Engeström \& Sannino, 2010).

According to Engeström and Sannino (2011), dilemmas are commonly expressed as hesitations and are represented by linguistic cues such as 'on the one hand ... on the other hand' or 'yes, but'. Conflicts take the form of resistance, disagreements, arguments and criticism. Conflicts are expressed with such linguistic cues as 'no, I disagree' and 'this is not true'. Critical conflicts are situations in which people face inner doubts that paralyse them when faced with contradictory motives and that is unsolvable by the subject alone. Double binds, according to Bateson (1972, cited in Engeström \& Sannino, 2011, p. 374), are processes in which actors repeatedly face pressing and equally unacceptable alternatives in their activity system, with seemingly no way out.

Engeström $(2015,2016)$ and Engeström and Sannino (2010) proposed four levels of contradictions that occur at different phases of the expansive learning process: primary and secondary contradictions (see Figure 1a), and tertiary and quaternary contradictions (see Figure 1b). Primary contradictions occur within each of the nodes of the central activity system. Secondary contradictions openly manifest between two or more nodes, notably between a new object and an old tool. Tertiary contradictions appear when representatives of culture introduce the object and motive of a culturally more advanced form of central activity into the dominant form of the central activity. Quaternary contradictions occur between a newly reorganised activity and its neighbouring activity systems. Figure $1(a, b)$ below shows a summary of the contradictions within the central and the interacting activity systems - that is, workplaces and VTIs.

Contradictions are significant factors within organisational change (Engeström \& Sannino, 2011). However, Leont'ev (1978) observed that for contradictions to become actual driving forces of expansive learning, one must identify a new, emerging object and turn it into a motive. Thus, systemic contradictions can be viewed as obstacles as well as potential energisers of change and development (Engeström, 2015). The double occurrence of contradictions as obstacles and energisers of change is useful in identifying and analysing the challenges encountered by the actors in collaborative activities. Analysing these challenges will provide a foundation for resolving them, allowing for a better implementation of collaborative activities. 


\section{Central Activity- MVP}

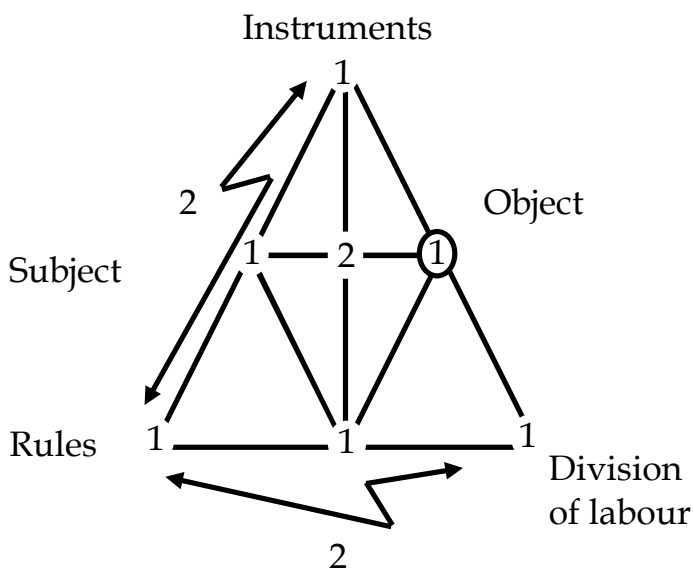

Contradictions:

1: Primary inner Contradictions; within each constituent component of central activity-MVP

2: Secondary Contradictions between constituents of central system

Figure 1a. Primary and secondary contradictions within the central activity system (adapted from Engeström, 2015).

$\begin{array}{cll}\text { Central Activity- MVP } & \begin{array}{l}\text { Culturally more advanced } \\ \text { central design \& system }\end{array} & \begin{array}{l}\text { Object activity: } \\ \text { workplaces }\end{array}\end{array}$

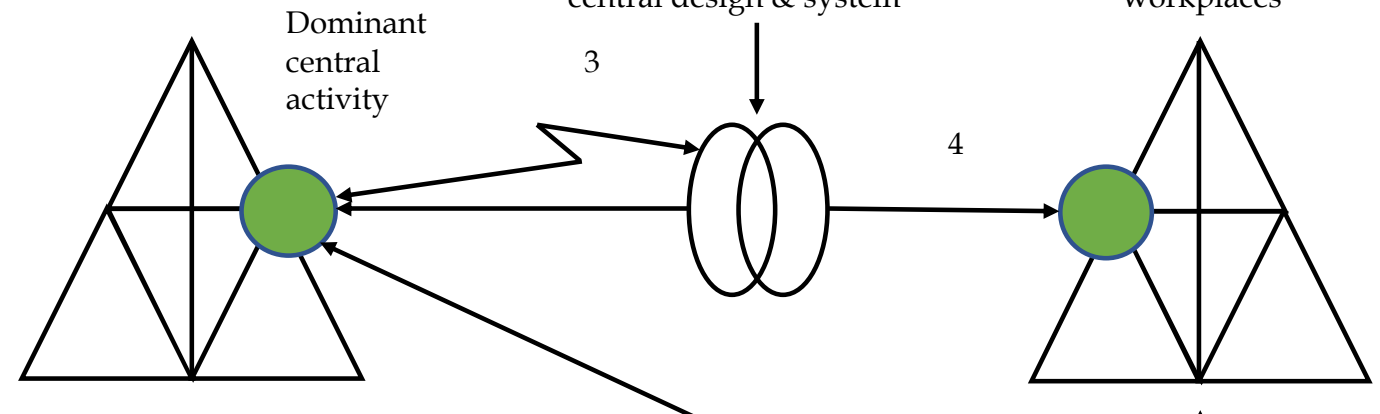

4

Contradictions:

3: Tertiary Contradiction between object of the dominant form of central system and culturally more advanced central design and system

4: Quaternary Contradictions between the central activity and its neighbor activities

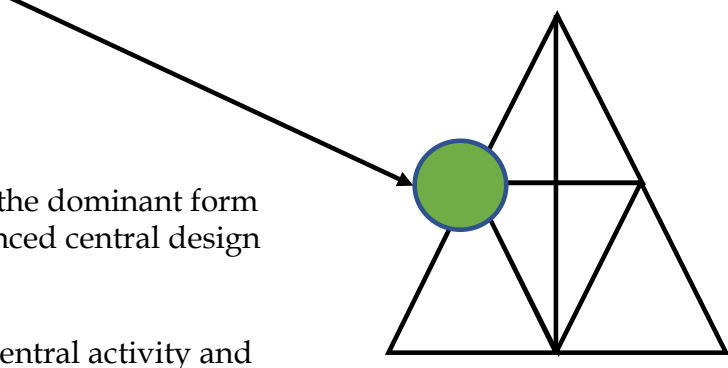

Object activity: VTIs

Figure $1 b$. Tertiary and quaternary contradictions between the central activity system and other activity systems (adapted from Engeström, 2015). 
However, while contradictions are a necessary engine of expansive learning in an activity system (Engeström \& Sannino, 2010), they are also a source of disturbances and multivoicedness, which create system instability (Engeström \& Sannino, 2011). For instance, in CHAT, multivoicedness occurs when individual actors bring in their histories from their social positions, affecting the division of labour in an activity system and, thus, becoming a source of instability (Daniels et al., 2007). Although these challenges are not categorised as contradictions, we observe that their occurrence does indicate the existence of contradictions, and resolving such challenges may offer learning opportunities. Based on this observation, Engeström and Sannino's (2011) methodological framework for the identification and analysis of discursive manifestations of contradictions has been adopted to analyse the challenges encountered in collaborative activities.

\section{Methodology}

A qualitative case study embedded with units of analysis (Creswell, 2013; Yin, 2014) was selected as the research design of this study. This design allowed for an intensive examination and an in-depth understanding of the case (Bryman, 2016). The MVP programme at Mukinga University in Uganda provided the main site of the study, while two VTIs and four workplaces became the embedded sites of the study. The sampled institutions and workplaces had participated in MVP collaborative activities for at least three years and were selected from the central and eastern regions of Uganda.

Patton (2015) and Bryman (2016) suggested the use of purposive sampling for selecting information-rich cases that allow the researcher to gain a deep understanding of the studied phenomena. The current study employed this approach in selecting its 22 participants in the following categories: 12 participants within the MVP programme (including mentors, students, action research project supervisors and project administrators), six participants (including administrators and teachers) from the two sampled VTIs in which the action research projects were implemented, and one manager/officer from each of the four workplaces (see Table 1). The names of the participants were assigned codes.

Semi-structured, in-depth individual interviews (Silverman, 2013; Tavakol \& Sandars, 2014), each of approximately 30-70 minutes, were conducted. Patton (2015) suggested the use of semi-structured, in-depth interviews to elicit rich information about people's experiences, opinions and knowledge of the issue under investigation. The interview guides focused on the challenges encountered in the implementation of collaborative activities and their effect on MVP students' learning. Three sets of interview guides were employed, depending on the respondent's role, position, and affiliation (see Table 1). 
Dinavence Arinaitwe, Louise Mifsud, Habib Kato \& Arne Ronny Sannerud

Table 1. Details about the study participants.

\begin{tabular}{|c|c|c|c|}
\hline $\begin{array}{l}\text { Type of data } \\
\text { source }\end{array}$ & $\begin{array}{l}\text { Duration } \\
\text { Hours \& } \\
\text { Minutes }\end{array}$ & Kind of respondents & Remarks: \\
\hline \multirow[t]{3}{*}{$\begin{array}{l}\text { Interviews } \\
\text { Field notes }\end{array}$} & $1: 30$ & $\begin{array}{l}\text { MVP students } \\
\text { Female student \& } \\
\text { Male student of Cohort } 2\end{array}$ & $\begin{array}{l}\text { Female: } 3 \text { years of teaching } \\
\text { Male: } 23 \text { years of trade and teaching }\end{array}$ \\
\hline & $1: 32$ & $\begin{array}{l}4 \text { Mentors for MVP } \\
2 \text { Senior mentors } \\
\text { - Mentor } 1 \text { \& Mentor } 2\end{array}$ & $\begin{array}{l}7 \text { and } 9 \text { years in mentoring and } \\
\text { over } 15 \text { years of practice }\end{array}$ \\
\hline & $1: 23$ & $\begin{array}{l}2 \text { Junior mentors } \\
\text { - Mentor } 3 \text { and Mentor } 4\end{array}$ & $\begin{array}{l}4 \text { years of mentoring and former } \\
\text { MVP students }\end{array}$ \\
\hline \multirow[t]{2}{*}{$\begin{array}{l}\text { Interviews } \\
\text { Field notes }\end{array}$} & $1: 38$ & $\begin{array}{l}\text { Action research project } \\
\text { supervisors } \\
\text { Supervisor } 1 \text { - female student, } \\
\text { and Supervisor } 2 \text { - male student }\end{array}$ & $\begin{array}{l}\text { Both } 9 \text { years of mentoring and over } \\
22 \text { years of practice }\end{array}$ \\
\hline & $2: 37$ & $\begin{array}{l}\text { NORHED project } \\
\text { administrators } \\
\text { Project administrator } 1,2,3\end{array}$ & $\begin{array}{l}\text { Female less than } 5 \text { years of work } \\
\text { experience } \\
\text { Males over } 5 \text { years in administration } \\
\text { and } 15 \text { years of practice }\end{array}$ \\
\hline $\begin{array}{l}\text { Interviews } \\
\text { Field notes }\end{array}$ & $2 \mathrm{hrs}$ & $\begin{array}{l}2 \text { Vocational teacher training } \\
\text { institutions (VTIs) } \\
\text { VTI 1: Institute administrator } 1 \text {, } \\
\text { Teacher } 1 \text {, Teacher } 2\end{array}$ & $\begin{array}{l}\text { VTI 1: } 9 \text { years collaborating with MVP } \\
\text { All participants including VTI } \\
\text { Administrator } 1 \text { had over } 10 \text { years of } \\
\text { work and teaching experience }\end{array}$ \\
\hline $\begin{array}{l}\text { Interviews } \\
\text { Field notes }\end{array}$ & $2 \mathrm{hrs}$ & $\begin{array}{l}\text { VTI 2: Institute administrator 2, } \\
\text { Teacher 3, Teacher } 4\end{array}$ & $\begin{array}{l}\text { VTI 2: } 7 \text { years collaborating with MVP } \\
\text { VTI Administrator 2: } 40 \text { years of } \\
\text { practice and teaching } \\
\text { Teachers: Below } 15 \text { years of experience }\end{array}$ \\
\hline $\begin{array}{l}\text { Interviews } \\
\text { Field notes }\end{array}$ & 55 mins & $\begin{array}{l}\text { Workplaces } \\
\text { Workplace 1: } \\
\text { Organisation - Government, } \\
\text { Qualification standards, Assess- } \\
\text { ment and certification } \\
\text { Officer } 1\end{array}$ & $\begin{array}{l}\text { Workplace 1: Over } 7 \text { years of } \\
\text { collaborating with MVP } \\
\text { Officer 1: Over } 25 \text { years of work and } \\
\text { teaching practice }\end{array}$ \\
\hline $\begin{array}{l}\text { Interviews } \\
\text { Field notes }\end{array}$ & 52 mins & $\begin{array}{l}\text { Workplace 2: } \\
\text { Organisation } \\
\text { - National Assessment board for } \\
\text { VET disciplines } \\
\text { Officer } 2\end{array}$ & $\begin{array}{l}\text { Workplace 2: Over } 7 \text { years of } \\
\text { collaborating with MVP } \\
\text { Officer 2: } 19 \text { years of work experience }\end{array}$ \\
\hline $\begin{array}{l}\text { Interviews } \\
\text { Field notes }\end{array}$ & 40 mins & $\begin{array}{l}\text { Workplace 3: } \\
\text { Industry - Large parastatal } \\
\text { dealing in Sugar manufacturing } \\
\text { Officer } 3\end{array}$ & $\begin{array}{l}\text { Workplace } 3: 4 \text { years of collaborating } \\
\text { with MVP } \\
\text { Officer 3: } 20 \text { years of practice and } \\
12 \text { years of training }\end{array}$ \\
\hline $\begin{array}{l}\text { Interviews } \\
\text { Field notes }\end{array}$ & 37 mins & $\begin{array}{l}\text { Workplace } 4 \text { : } \\
\text { Hotel, Tourism and Service } \\
\text { Training centre } \\
\text { Officer } 4\end{array}$ & $\begin{array}{l}\text { Workplace } 4: 9 \text { years of collaborating } \\
\text { with MVP } \\
\text { Officer } 4: 19 \text { years of training and work }\end{array}$ \\
\hline
\end{tabular}

Key: Respondent categories: 1) MVP project administrators; 2) MVP students, mentors and AR supervisors;

3) VTIs and Workplaces. 
For reliability purposes, the pretesting of the research tools to ascertain the appropriateness of the interview questions (Boeije, 2010) was done before the final data collection and the results were used to modify some aspects of the guides. Triangulation across the data by multiple participants (Creswell, 2013) was employed to ensure the validity of the findings. Data from various study sites by different categories of participants were compared. The participants' responses were also validated by showing the transcribed data to the respondents to confirm the credibility of the information and narrative account.

Through thematic analysis (Cohen et al., 2007), the texts were summarised based on pre-existing categories relating to the CHAT methodological framework for analysing contradictions. The process involved identifying, organising and offering insight into patterns of meaning (themes) across the data sets (Braun \& Clarke, 2012). Following the CHAT methodological framework (Engeström \& Sannino, 2011), the data were organised into three themes. The themes focussed on the conflicts, dilemmas, critical conflicts and double binds encountered in different phases of the MVP work. Taking on an inductive approach, excerpts were chosen for further analysis based on how well they answered the questions and how well the answers were articulated (Braun \& Clarke, 2012). Ethics approval was obtained from the Norwegian Centre for Research and Data and from the Uganda National Council of Science and Technology.

\section{Findings and discussion}

This research study focused on identifying and characterising challenges in learning through collaboration between an MVP programme, VTIs and workplaces to gain insight into how learning at MVP is influenced by the challenges encountered in collaborative activities. Findings revealed that challenges manifesting as discursive contradictions (conflicts, dilemmas, double binds, and critical conflicts) were encountered during the implementation of collaborative activities. Due to the interwoven nature of the manifestation of these contradictions, they are presented concurrently under three themes as they emerged from the different phases of MVP work processes namely: planning and implementation phase, supervision of learning, and participation in collaborative activities.

\section{Conflicts and dilemmas in the planning and implementation of collaborative activities}

The findings revealed that conflicts and dilemmas in the planning phase arose from the timing of collaborative activities interfering with other actors' activity plans. As Mentor 3 indicated:

The planning and timetabling for each semester are made but not adhered to at implementation. Sometimes, facilitators do not turn up due to not being informed on 
time. Therefore, activities are shifted, not completed in time, and sometimes a collision of events occurs. (Mentor 3)

A male MVP student also reported unsynchronised plans, stating that 'time for implementing action research projects was not tailored to match with my institutional activity plan.' As a result of unsynchronised plans, Teacher 1 from VTI 1 revealed, 'We used to reschedule other department activities when she [a female student] wanted to do her project activities.'

Findings as reflected in the excerpts reveal that conflicts and dilemmas in the planning phase arose from unharmonised activity plans that lead to collision of events. As a result, VTIs had to postpone or shift their planned activities to avoid collisions with events planned by the MVP programme. Even though the intentions of the collaborative activities were good, due to planning issues, the VTI actors perceived their implementation as interfering with their routine work. Unsynchronised plans can also limit participation in an activity, especially at workplaces in which work schedules are more predetermined and altering timetables is difficult. The structuring of workplace practices has been cited as inhibiting access that would assist employees in understanding workplace goals (Billett, 2001) while limiting students' abilities to gain sufficient practice in completing key tasks (Maxwell, 2014). Consequently, quaternary contradictions between the MVP programme and the VTIs that caused tensions in the planning of the activities at both systems necessitating rescheduling of events emerged. Engeström (2015) posited that quaternary contradictions occur between a newly reorganised activity and its neighbouring activity system. As such, disharmonies in activity plans indicate a need for joint planning of collaborative activities by all actors in order to identify workplace dynamics that may restrain participation and thereby plan accordingly to eliminate or avoid them.

Planning was regarded as a key aspect of organising collaborative activities by MVP staff and students. However, conflicts and dilemmas arose from short time frames allotted to collaborative activities as stated: 'The one day planned for field expedition was not enough to enable us to extensively acquire the intended skills. We worked hurriedly to accomplish the set field activities so that we could return to the university' (Female student). A mentor emphasised that: 'No, I don't agree with field expeditions being done in one day. MVP students should be given ample time to conduct in-depth field studies because learning occurs by doing' (Mentor 3).

Turning to action research projects, short time frames mainly affected the documentation process as a student, project administrator and mentor explained:

Action research processes are lengthy and cyclic, involving identifying the problem, suggesting possible actions, trying out actions, specifying the learning outcomes and evaluating if the problem is solved. But the time frames were short for all the processes that I had to use the institute holiday time. (Male student) 
Learning through collaboration between vocational teacher training institutions and workplaces

Action research activities require plenty of time to obtain the results. However, we [MVP] are constrained by university regulations where the students have to implement the projects in one semester - four months. We want to graduate students at the expense of the quality of research done. (Project administrator 2)

Due to limited time, the documentation of the thesis was done hurriedly. So synthesising, sorting out, logical sequencing of content becomes problematic. But the students have to complete the course after two years which was impossible for some. Flexibility is sometimes necessary. (Mentor 1)

The above quotations illustrate that the time aspect which was short often presented dilemmas and conflicts in the planning and implementing of collaborative activities. The time aspect became counterproductive to skills acquisition despite the MVP programme's intention to empower students to learn through interaction in collaborative activities. Contrary to the MVP programme's current practices, the authors argue that prolonged contact time in the field would facilitate a deeper engagement of students with tasks that would enrich their learning experiences, which are vital for action learning. In instances where practice is restricted due to time shortages, we view time as a contradiction in terms of both action at planning and interaction during execution of the planned activities. The current findings align with Maxwell (2014) who found that the structuring of work was affecting trainees' ability to complete sufficient practice of key tasks and gain the skills necessary for achieving competencies.

Action research, unlike mainstream research, in which field processes are shortened in most cases, tends to be lengthy, necessitating adequate planning and the allocation of a reasonable amount of time for each phase. Given the time constraints, the students could not run more than one action cycle even though the problematic situation was unresolved. If they had, the outcomes would have been compromised. As such, contradictions from time shortage not only interfered with the field processes but also the documentation aspect which ultimately affected the quality of the theses and the course completion rate by the MVP students.

The study findings imply that the time set by the university, as a rule, was limited in comparison to the actual time required to implement action research projects at the VTIs. Consequently, secondary contradictions occurred which according to Engeström and Sannino (2010), openly manifest between two or more nodes, notably between a new object and an old tool. In this case, a contradiction emerged between time as the rule set by the university and the objective which is the students' learning outcomes from the collaborative activities. We observe that action research as a new method for conducting research at the MVP required a new set of mediating artefact tools, instruments and rules if it was to thrive the old tradition and culture of conventional research approaches commonly employed at Mukinga University. 
Dilemmas and critical conflicts in the supervision of learning in collaborative activities

Whereas the supervision of learning in collaborative activities was acceptable at the university, this aspect was reported to be inadequate at the VTIs by VTI administrators and MVP students alike. An administrator noted that:

No formal structures for supervising learning from their [action research] projects on the ground [at VTIs]. No mentors here, we offer support, although it is voluntarily... Not even guidelines for supervising learning by the [MVP] students have been provided by the university. (VTI administrator 2 )

Similarly, a male student stated, 'Our mentors and supervisors cannot be here for all the project activities, so we have to work with our immediate bosses [VTI administrators]. But they lack commitment because they are not remunerated.'

As indicated in the findings, the absence of mentor guidance at the VTIs did not only limit but also halt learning. For instance, the MVP students faced the dilemma of progressing with the action research project activities in the absence of supportive supervision. And yet, being a new practice for most of the actors who were still learning its traditions, the authors observed the need for frequent support supervision for action research projects; which aspect was limited the VTIs. Moreover, mentor support or expert guidance has been identified as being crucial for workplace learning (Batholmeus \& Pop, 2019) without which could limit access to knowledge that would not be learned through discovery (Billett, 2001).

However, while Mukinga University seemed accustomed to allocating university professors as project supervisors, no consideration was given to workplace mentors, which are required in action research. Even though the MVP programme often included mentoring in its learning processes, it could not manage to convince the university to recruit workplace mentors. Not recruiting workplace mentors was found to slow the implementation processes of action research projects and thus limiting learning from these processes; which revealed a quaternary contradiction in the division of labour amongst actors. Engeström (2016) identified quaternary contradictions as occurring between a newly reorganised activity and its neighbouring activity systems.

The process of recruiting action research supervisors yielded critical arguments from mentors and project administrators alike, as described in the following excerpts:

I am a master's holder, but for the research supervision of MVP students, they consider those with a Doctor of Philosophy and yet they are inexperienced in action research. If our efforts are not recognised, why put in the work? (Mentor 4)

The project Administrator 3 clarified stating that: 'According to the university guidelines, a master's holder is not eligible to supervise a master's student. But due to the intensive nature of action research projects, mentors would be 
Learning through collaboration between vocational teacher training institutions and workplaces

recruited to support supervisors'. However, the idea of support mentors was not adhered to by Project administrator 2, who argued the following:

Why do we over-engage students under mentorship, and yet we expect them to learn by experience? They need to mature and become independent rather than being over-supported by mentors. A supervisor is a mentor. Why do you need both? I say no! (Project administrator 2)

Notably, the divergences in understanding the objectives and work processes of MVP by mentors and project administrators were a source of critical conflicts in the selection criteria for action research project supervisors. As emphasised by the findings, junior mentors were not considered for project supervision if they were seen to be academically under qualified, even if they were more experienced in action research processes than were some supervisors who held doctorate degrees. Whereas seniority has previously been used to determine opportunities to access new kinds of experiences, Billett (2001) argues that it sometimes inhibits access that would assist employees in the understanding of workplace goals. Despite the MVP students' projects being action-oriented coupled with the absence of workplace mentors, recruiting support mentors would provide for the timely and continuous implementation of the necessary processes. However, there seemed to be a gap between the intentions and actions of the MVP programme, as reflected by some project administrators' uncertainty about the role and value of support mentors in the learning of the MVP students. Not recognising the junior mentors' efforts in the supervision processes was tantamount to reducing the support given to the students, a condition that could have slowed students' learning as well as delayed the students' project and course completion time.

The inconsistencies in the understanding by the project administrators about the objectives of the collaborative activities and work methods reveal critical conflicts manifesting as tertiary contradictions. Engeström $(2015,2016)$ posited that tertiary contradictions occur when a more advanced objective and motive are introduced in the existing dominant culture of the central activity system. If these inconsistencies are not linked to the interpretation of the programme objective, they result in a power struggle amongst the MVP project administrators.

Delayed and contradictory guidance from mentors and action research project supervisors was reported to have affected the quality of the reports by MVP students, as indicated in the following excerpt:

We respond to the guidance, but sometimes it is late or contradicts different mentors and supervisors. Is there no standard way of doing things? Also, mentors are honestly busy with heavy workloads from their departments. However, delayed feedback on our work leads to delays in completing the tasks, which demoralises us. (Female student) 
The contradictory guidance was linked to MVP work methods that were contradictory to those of the university and other collaborating systems. A male MVP student reported, 'Outsourced facilitators were using teacher-centred strategies, contrary to the learner-centred strategies being employed here at the programme.'

Previous studies (Ellinger \& Cseh, 2007; Mårtensson et al., 2019) have indicated that teachers and workplace employees' heavy workloads often lead to a lack time to engage and guide students' learning in collaborative activities. Limited guidance by mentors could result in insufficient support for learning (Mikkonen et al., 2017) which in turn limits students' ability to transfer learning experiences to work context (Jackson et al., 2019). This study finding aligns with the previous studies by emphasising that MVP students were unable to complete the assigned tasks due to delayed feedback to their work which was attributed to the mentors' heavy workloads. We argue that providing timely and constructive criticism requires that mentors have adequate time to engage in reading the students' work and sharing their feedback - time that is currently limited.

Besides, the tensions between the two learning cultures - that is, teacher-centred and learner-centred approaches - intensified the contradictory nature of the feedback given to students. It can be noted that the two approaches are based on different principles and outcomes that need to be reconciled in one's work practices. Otherwise, these changes in work practices are a likely source of system tensions (Taylor, 2006). For instance, given that MVP students needed to integrate the learning needs of the two cultures, this 'back and forth' movement between old and new practices signifies a time lag which could slow their learning abilities.

Engeström and Sannino (2010) observed that because the elements of an activity system are interrelated, a change in any one of the elements affects the other elements. Consequently, because the MVP programme changed its objective by adopting new work methods and so was the need to ensure that the subjects could comply with these changes. In contrast to this, the MVP subjects (facilitators, mentors and project supervisors) were continuously recruited to the programme, with seemingly no proper orientation about the new culture. These subjects brought with them different sets of cultures and traditions that contradicted the new culture in the MVP programme. From a CHAT perspective, this is interpreted as multi-voicedeness (Engeström \& Sannino, 2011) in which different actors bring in histories from their different contexts. According to Daniels et al. (2007), multi-voicedeness affects the division of labour in an activity system, causing instability. 
Learning through collaboration between vocational teacher training institutions and workplaces

\section{Double binds and dilemmas in participation in collaborative activities}

Participation in collaborative activities was reported to be constrained by several aspects. These include the industry motive coupled with the lack of a government policy, as stated by the study respondents below:

Because we [workplace 3] have a policy on training, we are overwhelmed with too many requests for internships and field visits. Other industries are after profits and yet require experienced workers. If we do not train the people, where are we going to get the experience? Where is government policy? (Officer 3)

The above excerpt indicate that double binds in participation in collaborative activities arose mainly from the lack of a policy, both government and company.

A recent study conducted in Uganda (Kalanda et al., 2021) identified a lack of comprehensive systematic legislation to regulate and support IWC. It follows from the current study findings that without policy on IWC, accessing and sustaining interested partners would remain challenging. Findings further emphasised that without a policy, industries may not feel obliged to participate, and those that do may not be committed to the collaboration.

The absence of policy is not the only factor limiting participation in IWC (Mgonja, 2017), however, as the findings of this study also point to diverging interest between educational institutions and workplaces. The workplace officer reported that while the majority of the industries are after profits as their primary aim, they still require experienced workers. Due to the limited industry participation, training institutions have continued to produce ill-equipped graduates who are unable to compete in the labour market, and as such, employing them necessitates the expenditure of extra induction and orientation costs by industries. Moreover, a study conducted in Africa (Sá, 2013) emphasised that training institutions are not equipped with the necessary infrastructure to train students to meet the demands of industry. Consequently, we observe the need to increase industry participation in bridging the skills gaps in VET and vocational teacher education through instituting policies at various levels. Questioning the existence of government policy on IWC is a characteristic of a double bind, reflected as quaternary contradictions between the industry, government and training institutions. Quaternary contradictions, according to Engeström and Sannino (2010), occur between a newly reorganised activity and its neighbouring activity systems.

The failure of the MVP programme to share feedback on the data obtained from the VTIs and workplaces, and the absence of a collaboration focal person to convey this feedback, also limited the workplaces' participation in collaborative activities. The MVP male student revealed that:

After the field visits, we compile the reports, but these findings are never shared with the actors. We [MVP students] come out with different views, ideas, and suggestions that would help the workplaces [VTIs] to improve though this information is shelved. (Male student) 
Similarly, an institute administrator noted, 'But no time has been set aside to share feedback on information obtained from us [VTIs]. There is not even a collaboration focal person to coordinate those [collaborative] activities' (Institute administrator 1).

The findings from the above excerpts indicated the failure to share feedback with the actors implying a one-way collaboration. The authors argue that to qualify as collaboration, the actors in the collaborative activities need to work together toward a common objective for mutual benefit. One-way collaboration as was identified in the findings reflects the lack of mutual benefit to workplaces that could lead to the loss of trust thus creating resistance to sharing certain information. A previous study (Choy et al., 2016) emphasised that increased trust amongst partners calls for recognition of the mutual benefits and cost and becoming aware of how to pursue the goals. Therefore, the lack of mutual trust on the side of training institutions as potential partners by industries could lead to a lack of collaboration in the future (Ankrah \& Al-Tabbaa, 2015); a gap that MVP needs to bridge. MVP's failure to share feedback with collaborating actors undermines the collaborative efforts necessary to create and sustain the collaboration. The present findings seem to contradict previous studies and Engeström's (2000, 2015) view that creating a shared vision for the expansive solution of the contradiction calls for collaborative analysis and modelling. Under such circumstances, it invites questions about how successful and sustainable such collaborations are if they only serve the interest of the initiator. Sharing feedback with the actors would not only stimulate and sustain collaboration but also inform the learning content of the MVP programme as well as improve the public image by showing that the programme is contributing to solving society's needs.

The findings also point to the absence of collaboration focal persons commonly referred to as boundary spanners. Sjöö and Hellström (2019) indicated that boundary spanners are vital in establishing and maintaining communication channels between actors. As such, the absence of boundary spanners would leave collaborations on the peripheries, with only a few individuals involved, which limit participation (Sá, 2013). Indeed, this study finding emphasises that the absence of a collaboration focal person limited participation in the collaborative activities that resulted in uncoordinated, delayed and collision of events. These interferences in execution of the collaborative activities seem to have constrained the achievement of the collaboration objectives. We observe that the role of collaboration focal persons - key players in information sharing and resource and human mobilization - should not be underrated. Efforts are needed to ensure the incorporation of collaboration focal persons, allowing for improved coordination and implementation of collaborative activities. 


\section{Conclusion}

This study aimed to identify and characterise the challenges of learning through collaboration between an MVP, VTIs and workplaces. Challenges manifesting as discursive contradictions in the implementation of collaborative activities were mainly systemic and rooted within the central activity system (MVP programme), although external forces were also at play. Engaging in collaborative activities involving different learning and research cultures in the MVP resulted in a lack of harmony with those of other interacting systems. Contradictions in the planning and implementation phase were linked to short time frames of collaborative activities and unsynchronised activity plans. In the supervision phase, contradictions arose from a lack of a common understanding of the MVP objectives and work methods. The lack of feedback to actors, lack of a collaboration focal person and lack of policies both government and workplace on IWCs inhibited participation in collaborative activities. These contradictions were found to delay the project completion time and decrease MVP students' academic concentration, thus lowering the quality of their work.

Based on the study findings, we question whether the MVP programme may not have been appropriate for the contextual conditions in which it had to function and whether the collaborative activities will be sustainable. There is an urgent need to resolve the identified contradictions for the effective implementation and sustainability of the collaborative activities. In the short term, the MVP programme needs to continuously orient and update the actors to its work practices and to actively engage them in organising the collaborative activities. The actors' understandings of the MVP objectives, work methods and collaborative activities need to be harmonised to afford students effective learning and efficient supervision. A feedback system for all actors should be put into place to achieve the mutual benefits of collaboration. In the long term, there is a need to review the MVP programme and institute measures for resolving the identified contradictions to ensure system stability. Future VET actors undertaking IWC need to consider how best to work within the given context before introducing new ideas. In the study, we address critical areas of concern for VET practitioners who wish to establish linkages with the workplaces by contributing knowledge on the challenges facing learning through collaboration in the field of vocational teacher education particularly the African context.

The limitation of this study is that it has only identified and characterised the contradictions encountered in learning through collaboration between the MVP, vocational teacher training institutions and workplaces. We suggest that future research should seek to identify possible strategies for resolving these contradictions. 


\section{Acknowledgements}

We thank the Norwegian Programme for Capacity Development in Higher Education and Research and Development (NORHED) - MVP project 2013-2018 for supporting and funding this study.

\section{Disclosure statement}

The author declares no competing interest.

\section{Notes on contributors}

Dinavence Arinaitwe is Ph.D. Candidate in Educational Sciences for Teacher Education, Oslo Metropolitan University, Norway, and Vocational and Technical Teacher Educator at Kyambogo University, Uganda. Her research areas are vocational education and training, action research, and vocational pedagogy.

Louise Mifsud is a Professor at the Department of primary and secondary teacher education, Oslo Metropolitan University, Norway. Her research areas are teacher education, mobile learning, digital competence, and cyber ethics.

Habib Kato is an associate professor at the Department of Agriculture, Kyambogo University, Uganda. His research areas are animal production; ruminant nutrition and vocational teacher education.

Arne Ronny Sannerud is a Professor in Vocational Pedagogy at the University College of Vocational Education, Norway. His research includes vocational education and training, simulator training, and action research. 


\section{References}

Andersson, P., \& Köpsén. S. (2019). VET teachers between school and working life: Boundary processes enabling continuing professional development. Journal of Education and Work, 32(6-7), 537-551.

https:/ / doi.org/10.1080/13639080.2019.1673888

Ankrah, S., \& Al-Tabbaa, O. (2015). Universities-industry collaboration: A systematic review. Scandinavian Journal of Management, 31(3), 387-408. https:// doi.org/10.1016/j.scaman.2015.02.003

Arinaitwe, D. (2021). Practices and strategies for enhancing learning through collaboration between vocational teacher training institutions and workplaces. Empirical Research in Vocational Education and Training, 13. https://doi.org/10.1186/s40461-021-00117-z

Arinaitwe, D., \& Sannerud, A. R. (2019). Analysing the interplay between institutional-based and workplace learning. Scandinavian Journal of Vocations in Development, 4(1), 109-135. https://doi.org/10.7577/sjvd.3249

Batholmeus, P., \& Pop, C. (2019). Enablers of work-integrated learning in technical vocational education and training teacher education. International Journal of Work-Integrated Learning, 20(2), 147-159.

Billett, S. (2001). Learning in the workplace: Strategies for effective practice. Routledge. Boeije, H. (2010). Analysis in qualitative research. Sage.

Bound, H. (2011). Vocational education and training teachers' professional development: Tensions and context. Studies in Continuing Education, 33(2), 107-119. https:/ / doi.org / 10.1080/0158037X.2011.554176

Braun, V., \& Clarke, V. (2012). Thematic analysis. In H. Cooper, P. M. Camic, D. L. Long, A. T. Panter, D. Rindskopf, \& K. J. Sher (Eds.), APA handbook of research methods in psychology (Vol. 2). Research designs: Quantitative, qualitative, neuropsychological, and biological (pp. 57-71). American Psychological Association. https:/ / doi.org/10.1037/13620-004

Bryman, A. (2016). Social research methods (5th ed.). Oxford University Press.

Choy, S., Kemmis, R., \& Green, A. (2016). Theorising partnerships for site-based education development in vocational education and workplace learning. $E d u-$ cation Action Research, 24(3), 334-352. https://doi.org/10.1080/09650792.2016.1178155

Cohen, L., Manion, P., \& Morrison, K. (2007). Research methods in education (6th ed.). Routledge.

Creswell, J. (2013). Qualitative inquiry and research design: Choosing among five approaches (3rd ed.). Sage.

Daneils, H., Leadbetter, J., Soares, A., \& MacNab, N. (2007). Learning in and for cross-school working. Oxford Review of Education, 33(2), 125-142.

https://doi.org/10.1080/03054980701259469 
Ellinger, A., \& Cseh, M. (2007). Contextual factors influencing the facilitation of others' learning through everyday work experiences. Journal of Workplace Learning, 19(7), 435-452. https:// doi.org/10.1108/1366562071081938

Engeström, Y. (2001). Expansive learning at work: Towards an activity theoretical reconceptualization. Journal of Education and Work, 14(1), 133-156. https:/ / doi.org/10.1080/13639080020028747

Engeström, Y. (2015.). Learning by expanding: An activity-theoretical approach to developmental research (2nd ed.). Cambridge University Press.

Engeström, Y. (2016). Studies in expansive Learning: Learning what is not yet there. Cambridge University Press.

Engeström, Y., \& Sannino, A. (2010). Studies of expansive learning: Foundations, findings, and future challenges. Educational Research Review, 5(1), 1-24. https:/ / doi.org/10.1016/j.edurev.2009.12.002

Engeström, Y., \& Sannino, A. (2011). Discursive manifestations of contradictions in organizational change efforts: A methodological framework. Journal of Organizational Change Management, 24(3), 368-387. https:/ / doi.org/10.1108/09534811111132758

Fjellström, M. (2014). Vocational education in practice: A study of work-based learning in a construction programme at a Swedish upper secondary school. Empirical Research in Vocational Education and Training. 6(2), 1-20.

http:/ / www.ervet-journal.com/content/6/1/2

Flynn, M. C., Pillay, H., \& Watters, J. (2016). Industry-school partnerships: Boundary crossing to enable school to work transitions. Journal of Education and Work, 29(3), 309-331. https:/ / doi.org/10.1080/13639080.2014.934789

Guimon, J. (2013). Promoting university-industry collaboration in developing countries. World Bank. https://www.scribd.com/document/264806771/Promoting-University-Industry-Collaboration-in-Developing-Countries

Jackson, D., Fleming, J., \& Rowe, A. (2019). Enabling the transfer of skills and knowledge across classroom and work contexts. Vocations and Learning, 12(3), 459-478. https:// doi.org/10.1007/s12186-019-09224-1

Kalanda, E., Malenya, F., \& Otiende, E. (2021). Systematic legislation a stimulation for meaningful inclusion of work-integrated learning in higher education curricula in Uganda. Journal of Research $\mathcal{E}$ Methods in Education, 11(1), 24-38. https:/ / doi.org/10.9790/7388-1101032438

Kitagaana, Z. (2018). Constraints to university-industry linkages in Uganda: Perceptions of dons at public university. African Journal of Education, Science, and Technology, 5(1), 140-149.

https:/ / ajest.info/index.php/ajest/article/view/603

Köpsén, S., \& Andersson, P. (2018). Boundary process in connection with students' workplace learning: Potentials for VET teachers' continuing professional development. Nordic Journal of Vocational Education and Training, 8(1), 58-75. https:/ / doi.org/10.3384/njvet.2242-458X.188158 
Leont'ev, A. (1978). Activity, consciousness, and personality. Prentice-Hall.

Mårtensson, A., Andersson, P., \& Nyström, S. (2019). A recruiter, a matchmaker, a firefighter: Swedish vocational teachers' relational work. Nordic Journal of Vocational Education and Training, 9(1), 89-110.

https:/ / doi.org/10.3384/njvet.2242-458X.199189

Maxwell, B. (2014). Improving workplace learning of lifelong learning sector trainee teachers in the UK. Journal of Further and higher Education, 38(3), 377399. https:/ / doi.org/10.1080/0309877X.2013.831036

Mgonja, C. (2017). Enhancing the university-industry collaboration in developing countries through best practices. International Journal of Engineering Trends and Technology, 50(4), 216-225.

Mjelde, L., \& Daly, R. (2012). Aspects of vocational pedagogy as practice: Decolonizing minds and negotiating local knowledge. International Journal of Training Research, 10(1), 43-57. https:// doi.org/10.5172/ijtr.2012.10.1.43

Mikkonen, S., Pylvas, L., Nokelainen, P., \& Postareff, L. (2017). Guiding workplace learning in vocational education and training: A literature review. Empirical Research in Vocational Education and Training, 9(9), 1-22. https:/ / doi.org/10.1186/s40461-017-0053-4

Ministry of Education and Sports. (2012). Skilling Uganda: BTVET Strategic Plan 2012/13 to 2021/2. https://www.ilo.org/dyn/youthpol/en/equest.fileutils.dochandle?p_uploaded_file_id=153

Ministry of Education and Sports. (2019a). The technical vocational education and training (TVET) policy. https:/ / www.education.go.ug/wp-content/uploads/2020/05/FINAL-TVET-POLICY_IMPLEMENTATION-STANDARDS_IMPLEMENTATION-GUIDELINES_19TH_MAY_2020.pdf

Ministry of Education and Sports. (2019b). The national teacher policy.

Mushemeza, E. (2016). Opportunities and challenges of academic staff in higher education in Africa. International Journal of Higher Education, 5(3), 236-246. https:/ / doi.org/10.5430/ijhe.v5n3p236

Okello, B. (2011). 80 complexities and contradictions in technical and vocational education policy in Uganda. Journal of Research in Education and Society, 2(1), 180-194.

Okello, B. (2014). A history of technical education in Uganda 1877-2005. https:/ / www.academia.edu/7320439/HISTORY_OFTECHNICAL_EDUCATION_IN_UGANDA

Organisation for Economic Co-operation and Development (OECD). (2010). Learning for jobs: Report of the OECD reviews of vocational education and training.

Patton, M. Q. (2015). Qualitative research and evaluation methods (4th ed.). Sage.

Pertuze, J., Calder, E., Greitzer, E., \& Lucas, W. (2010). Best practices for industryuniversity collaboration. Mitsloan Management Review, 51(4), 82-90.

Rojewski, J. W. (2009). A conceptual framework for technical and vocational education and training. In R. Maclean, \& D. Wilson (Eds.), International handbook 
of education for the changing world of work: Bridging academic and vocational learning (pp. 19-39). Springer. https://doi.org/10.1007/978-1-4020-5281-1_2

Rybnicek, R., \& Konigsgruber, R. (2019). What makes industry-university collaboration succeed? A systematic review of the literature. Journal of Business Economics, 89, 221-250. https:/ / doi.org/10.1007/s11573-018-0916-6

Sá, C. M. (2013). Perspectives of industry's engagement with African universities. African Association of Universities. http://www.heart-resources.org/wp-content/uploads/2015/09/Report-on-University-Industry-Linkages.pdf

Said, A. (2018). Vocational teaching - Learning through the eyes of undergraduate vocational students in Malta: A qualitative exploratory study. International Journal for Research in Vocational Education and Training, 5(1), 42-63. https:/ / doi.org/10.13152/IJRVET.5.1.3

Sannerud, A. R. (2019). Vocational pedagogy . In T. O. Halvorsen (Ed.), Sharing knowledge transforming societies (pp. 231-248). African Minds.

Silverman, D. (2013). Doing qualitative research (4th ed.). Sage.

Sjöö, K., \& Hellström, T. (2019). University-industry collaboration: A literature review and synthesis. Industry and Higher Education, 33(4), 275-285. https:/ / doi.org/10.1177/0950422219829697

Tavakol, M., \& Sandars, J. (2014). Quantitative and qualitative methods in medical education research: AMEE Guide No 90: Part II. Medical Teacher, 36(10), 838-848. https:// doi.org/10.3109/0142159X.2014.915297

Taylor, A. (2006). The challenges of partnership in school-to-work transition. Journal of Vocational Education and Training, 58(3), 319-336. https:/ / doi.org/10.1080/13636820600955716

United Nations. (2015). Transforming our world: The 2030 agenda for sustainable development. United Nations Department of Economic and Social Affairs. https:/ / sustainabledevelopment.un.org/post2015/transformingourworld/publication

Yin, K. R. (2014). Case study research: Design and methods. Sage. 